\title{
Deep brain stimulation of the pallidum is effective and might stabilize striatal $D_{2}$ receptor binding in myoclonus-dystonia
}

\author{
R. J. Beukers ${ }^{1}$, M. F. Contarino ${ }^{1}$, J. D. Speelman ${ }^{1}$, P. R. Schuurman ${ }^{2}$, J. Booij ${ }^{3}$ and Marina A. J. Tijssen ${ }^{1 *}$ \\ 1 Department of Neurology, Academic Medical Centre, University of Amsterdam, Amsterdam, Netherlands \\ 2 Department of Neurosurgery, Academic Medical Centre, University of Amsterdam, Amsterdam, Netherlands \\ ${ }^{3}$ Department of Nuclear Medicine, Academic Medical Centre, University of Amsterdam, Amsterdam, Netherlands
}

\section{Edited by:}

Ryuji Kaji, Tokushima University

Hospital, Japan

Reviewed by:

Daniel Truong, The Parkinson and Movement Disorder Institute, USA

Carlo Colosimo, Sapienza University of Rome, Italy

*Correspondence:

R. J. Beukers and Marina A. J. Tijssen, Department of Neurology, Academic Medical Center, University of

Amsterdam, Meibergdreef 9, 1105 AD Amsterdam, Netherlands.

e-mail: r.j.beukers@mca.nl;

m.a.tijssen@amc.uva.nl

\begin{abstract}
Purpose: To assess clinical efficacy of deep brain stimulation (DBS) of the pallidum in Myoclonus-Dystonia (M-D) patients, and to compare pre- and post-operative striatal dopamine D2 receptor availability. Methods: Clinical parameters were scored using validated rating scales for myoclonus and dystonia. Dopamine D2 receptor binding of three patients was studied before surgery and approximately 2 years post-operatively using 123I-iodobenzamide Single Photon Emission Computed Tomography. Two patients who did not undergo surgery served as controls. Results: Clinically, the three M-D patients improved 83,17 , and $100 \%$, respectively on the myoclonus rating scale and 78,23 , and $65 \%$ on the dystonia rating scale after DBS. Dopamine D2 receptor binding did not change after surgery. In the two control subjects, binding has lowered further. Conclusion: These findings confirm that DBS of the pallidum has beneficial effects on motor symptoms in M-D and suggest this procedure might stabilize dopamine D2 receptor binding.
\end{abstract}

Keywords: myoclonus, dystonia, IBZM-SPECT, DBS

\section{INTRODUCTION}

Myoclonus-Dystonia (M-D) is a movement disorder clinically characterized by myoclonic jerks and dystonic postures or movements of the upper body, often combined with psychiatric symptoms such as depressed mood or anxiety (Zimprich et al., 2001). M-D is autosomal dominantly inherited and is frequently caused by mutations in the epsilon-sarcoglycan gene (SGCE) on chromosome 7q21 (DYT-11; Klein, 2003; Asmus and Gasser, 2004).

Deep brain stimulation (DBS) of the globus pallidus internus (GPi) is currently the most promising technique for treatment of patients with severe medically refractory dystonia. Three randomized controlled trials investigated this procedure in primary generalized dystonia and found significant clinical improvement on the Burke-Fahn-Marsden Dystonia Rating Scale (BFMDRS) after 6 and 12 months (Vidailhet et al., 2005; Kupsch et al., 2006; Valldeoriola et al., 2010), sustained after a 3-year follow up period (Vidailhet et al., 2007). More specifically on M-D, a recent study of GPi-DBS in five M-D patients found striking beneficial effects on dystonia and particularly on myoclonus (Azoulay-Zyss et al., 2011) as did another study, comparing GPi-DBS and thalamic nucleus ventralis intermedius (VIM)-DBS in $10 \mathrm{M}-\mathrm{D}$ patients with either target (Gruber et al., 2010). Additional case reports describe good response of motor symptoms after VIM-DBS or GPi-DBS in M-D patients (Cif et al., 2004; Foncke et al., 2007; Kuncel et al., 2009; Kurtis et al., 2010). To summarize, GPi-DBS has been reported in only $19 \mathrm{M}-\mathrm{D}$ patients so far and positive results were reported, although no class I or II trial has been reported.
Neuronal models of dystonia have postulated hyperactivity of the direct putamen-pallidal pathway with reduced inhibitory output of the internal segment of the globus pallidus (GPi), with subsequently increased thalamic input to the (pre-) motor cortex, resulting in excessive motor cortex excitation (Vitek, 2002). Previously, our group showed statistically significantly lower striatal dopamine D2 receptor (D2R) binding in M-D patients, possibly due to decreased D2R availability or increased levels of endogenous dopamine and consequently competitive D2R occupancy (Beukers et al., 2009), consistent with a mouse model showing increased striatal dopamine and metabolites in SGCE knockout mice (Yokoi et al., 2006).

In Parkinson's disease several studies regarding the effect of DBS on D2R have been published (Abosch et al., 2003; Hilker et al., 2003; Hesse et al., 2008). Acute stimulation (stimulator on versus off) of the subthalamic nucleus (STN) did not induce sufficient endogenous dopamine to influence D2R binding significantly (Abosch et al., 2003; Yokoi et al., 2006; Hesse et al., 2008). Hesse and co-workers showed a statistically significant increase of IBZM binding to D2R after STN-DBS (pre- versus post-surgery; stimulator on; Abosch et al., 2003). However, the opposite was found after GPi-DBS (Nakajima et al., 2003). To our knowledge, studies comparing D2R availability before and after DBS have never been performed in any type of dystonia. The first aim of this study is to report the clinical effects of GPi-DBS on M-D patients who had surgery in our center. Moreover, as our previous study showed decreased striatal receptor binding in M-D patients (Vidailhet et al., 2005), our second aim was to examine whether D2R may increase (reflecting normalization) after GPi-DBS. 


\section{MATERIALS AND METHODS PATIENTS}

Three male M-D patients (ages 29, 48, and 48 years) at the time of the first single photon emission computed tomography (SPECT) scan, in whom the DYT-11 mutation was genetically confirmed (1 basepair insertion: 885Tins, $304 \mathrm{C}>\mathrm{T}$ and 619-620 delAG, respectively), were studied using [123-I]-IBZM SPECT before and approximately 2 years after bilateral simultaneous GPi DBS implant. Surgery was performed under local anesthesia, with the use of intraoperative microelectrode recordings and test stimulation. Post-operative CT-scans were co-registered with the framebased pre-operative MRI to confirm positioning of the electrodes in the GPi. The pre-operative [123-I]-IBZM SPECT scans of these 3 patients and of 12 other mutation-positive M-D patients were reported previously (Beukers et al., 2009). From this same study population, two genetically confirmed M-D patients who had not received DBS agreed to be re-scanned after approximately 3.5 years to serve as controls (both mutation 619-620 delAG, related to subject 3). None of the patients had a history of neuroleptic drug usage or any other dopamine receptor blocking agent. Dystonia and myoclonus were assessed at the time of the first and second scan using the BFMDRS (Burke et al., 1985) and the Unified Myoclonus Rating Scale (Frucht et al., 2002). Subject 2 was the only one who had received Botulinum toxin injection in cervical muscles approximately 9 weeks prior to the first scan; for this reason, in this subject the myoclonus and dystonia scores of his pre-operative assessment were used approximately 3 months after his last botulinum toxin injection. Patient characteristics and timeframes of scanning are summarized in Table 1. All subjects gave written informed consent and the study was approved by the local medical ethics committee.

\section{DATA ACQUISITION}

The IBZM-SPECT methods, for data acquisition and processing were identical for all scans (Beukers et al., 2009). Shortly, subjects received a potassium iodide solution to block thyroid uptake of free radioactive iodide. Approximately $100 \mathrm{MBq}$ of [123-I]-IBZM was given intravenously as bolus, followed by continuous infusion of $25 \mathrm{MBq} / \mathrm{h}$ to achieve unchanging regional brain activity levels
(Laruelle et al., 1995; Booij et al., 1997). Acquisition of the images was started $2 \mathrm{~h}$ after the bolus injection (Frucht et al., 2002).

Single photon emission computed tomography studies were performed using a 12-detector single slice brain-dedicated scanner (Neurofocus 810, which is an upgrade of the Strichmann Medical Equipment).

\section{DATA PROCESSING}

Attenuation correction of all images was performed (Ishibashi et al., 2009). Images were reconstructed in 3D mode (http://www.neurophysics.com). These 3D reconstructed images were then randomly numbered by an independent physician and analyzed blindly by one observer (R. J. Beukers). For quantification, a region-of-interest (ROI) analysis was performed. For analysis of striatal [123-I]-IBZM binding, the ratio of specific striatal to occipital binding (representing non-specific binding) was calculated by averaging four transverse slices, representing the most intense striatal binding. Standard templates with fixed ROIs were manually placed on the striatum and occipital cortex, and then the ratio of striatal to occipital binding (SOR) was calculated as follows: (total striatal binding - occipital binding)/occipital binding. The analyses of the 3D reconstructed images was performed again the following week, variability and the intraclass correlation coefficient were then calculated to assess intra-observer reliability.

\section{DATA ANALYSIS}

Symmetry of the left and right SORs was calculated using a Wilcoxon signed ranks test in all patients, this analysis was performed using SPSS version 17. Because the number of patients is too small to perform meaningful statistics between groups, none were calculated. Instead, all data is presented in Tables $\mathbf{1}$ and $\mathbf{2}$. All videos used to assess the UMRS and BFMDRS were scored by a movement disorder specialist (J. D. Speelman).

\section{RESULTS}

\section{CLINICAL CHARACTERISTICS}

Patient characteristics are summarized in Table 1. The patients who underwent DBS all reported significant improvement of their symptoms at the time of the second [123-I]-IBZM SPECT scan.

Table 1 | Clinical characteristics.

\begin{tabular}{|c|c|c|c|c|c|c|c|c|}
\hline$N$ & $M / F$ & Age & $\begin{array}{l}\text { BFMDRS/UMRS at first } \\
\text { scan (before GPi-DBS) }\end{array}$ & $\begin{array}{l}\text { BFMDRS/UMRS at second } \\
\text { scan (after GPi-DBS) }\end{array}$ & $\%$ Change & $\begin{array}{l}\text { Stimulation } \\
\text { settings L/R }\end{array}$ & $\begin{array}{l}\text { Time after } \\
\text { GPi DBS }\end{array}$ & $\begin{array}{l}\text { Time between } \\
\text { scans (months) }\end{array}$ \\
\hline 1 & M & 29 & $18 / 46$ & $4 / 8$ & $-78 /-83$ & $\begin{array}{l}3.5 \mathrm{~V} 120 \mathrm{us} / 130 \mathrm{~Hz} \\
2.8 \mathrm{~V} 90 \mathrm{us} / 130 \mathrm{~Hz}\end{array}$ & 27 months & 30 \\
\hline 2 & M & 48 & $26 / 70^{*}$ & $20 / 58$ & $-23 /-17$ & $\begin{array}{l}3.2 \mathrm{~V} 60 \mathrm{us} / 130 \mathrm{~Hz} \\
3.0 \mathrm{~V} 60 \mathrm{us} / 130 \mathrm{~Hz}\end{array}$ & 12 months & 28 \\
\hline 3 & M & 48 & $\begin{array}{l}\text { 20/100 } \\
\text { BFMDRS/UMRS at first } \\
\text { scan }\end{array}$ & $\begin{array}{l}7 / 0 \\
\text { BFMDRS/UMRS at second } \\
\text { scan }\end{array}$ & $-65 /-100$ & $\begin{array}{l}3.0 \mathrm{~V} 60 \mathrm{us} / 130 \mathrm{~Hz} \\
-\end{array}$ & 19 months & 29 \\
\hline 4 & M & 53 & $4 / 4$ & $4 / 4$ & $0 / 0$ & - & No DBS & 43 \\
\hline 5 & M & 51 & $26 / 12$ & $6 / 10$ & $-77 /-17$ & - & No DBS & 46 \\
\hline
\end{tabular}

N, subject; M, male; BFMDRS, Burke Fahn Marsden Dystonia Rating Scale; UMRS, Unified Myoclonus Rating Scale; GPi-DBS, globus pallidus internus deep brain stimulation; age, age at time of first [123-I]-IBZM SPECT scan. *Scoring performed before DBS, 15 months after first scan. 
Table 2 | SORs before and after GPi-DBS.

\begin{tabular}{|c|c|c|c|c|c|c|}
\hline \multirow[t]{2}{*}{ Subject } & \multicolumn{3}{|c|}{ Before GPi-DBS } & \multicolumn{3}{|c|}{ After GPi-DBS } \\
\hline & SOR left & SOR right & SOR mean & SOR left & SOR right & SOR mean \\
\hline 1 & 0.90 & 0.85 & 0.87 & 0.83 & 0.89 & 0.86 \\
\hline 2 & 1.06 & 0.90 & 0.98 & 1.21 & 1.07 & 1.14 \\
\hline 3 & 1.04 & 1.06 & 1.05 & 0.86 & 0.93 & 0.89 \\
\hline \multicolumn{4}{|c|}{ No DBS, first scan } & \multicolumn{3}{|c|}{ No DBS, second scan } \\
\hline 4 & 1.14 & 1.14 & 1.14 & 0.93 & 0.82 & 0.87 \\
\hline 5 & 1.05 & 0.94 & 1.00 & 0.66 & 0.73 & 0.69 \\
\hline
\end{tabular}

GPi-DBS, globus pallidus internus deep brain stimulation; SOR, striatal to occipital ratio.

When formally scored on video, GPi-DBS patients had improved 78,23 , and $65 \%$, respectively on the BFMDRS and 83,17 , and $100 \%$ on the UMRS. One patient not having undergone DBS improved on the BFMDRS (77\%) and on the UMRS (17\%), the other patient showed no change on the clinical rating scales.

\section{[123-I]-IBZM SINGLE PHOTON EMISSION COMPUTED TOMOGRAPHY}

Variability between the two analyses performed with a 1-week interval was $3.7 \%$, with an intraclass correlation coefficient of 93.5\%. Results of second analysis are presented in Table 2. No asymmetry between left and right SORs was found, either at the first or at the second scan (first scan $p=0.50$; second scan $p=0.69$ respectively). No consistent differences between the measurement before and after DBS are discernable (SOR mean: one unchanged, one higher, one lower). Of both subjects who did not have DBS, the mean SOR was lower after surgery compared to before surgery.

\section{DISCUSSION}

Globus pallidus internus-DBS improved greatly myoclonus and, to a lesser extent dystonia, consistent with earlier studies (Gruber et al., 2010; Azoulay-Zyss et al., 2011). In our previous study, we found decreased D2R in $15 \mathrm{M}-\mathrm{D}$ patients, possibly reflecting an increase in endogenous striatal dopamine (Beukers et al., 2009). In this study, no large effect of GPi-DBS on D2R binding potential in M-D patients was observed despite obvious clinical benefit on myoclonus and dystonia rating scales. This lack of change is consistent with studies regarding STN-DBS in Parkinson's disease, but not consistent with the GPi-DBS study describing normalization (decrease) of D2R binding potential in Parkinson's disease. A drawback of this study is the small number of patients, rendering it impossible to reach statistical significance. It was not our intention to reach a predefined level of significance as much as it was to report an interesting finding. Of course, a much larger sample size

\section{REFERENCES}

Abosch, A., Kapur, S., Lang, A. E., Hussey, D., Sime, E., Miyasaki, J., Houle, S., and Lozano, A. M. (2003). Stimulation of the subthalamic nucleus in Parkinson's disease does not produce striatal dopamine release. Neurosurgery 53, 1095-1102.

Asmus, F., and Gasser, T. (2004). Inherited myoclonus-dystonia. $\mathrm{Adv}$. Neurol. 94, 113-119.

is needed to warrant firmer conclusions. However, interestingly, in both M-D patients who did not had surgery, a clear decrease of D2R binding was observed. The changes on the clinical rating scales in patient 5 might be attributed to symptom variability over time or variable effect of medication. In addition, this patient reported being very anxious at the time of the first video-scoring and concomitant worsening of his motor symptoms. At the time of the second video-scoring, the patient reported being much less anxious, while medication had not changed in the mean time.

Progression of $\mathrm{M}-\mathrm{D}$ could be associated with a further decline of D2R, which may be mitigated by DBS of the GPi. Although in our previous study we did not find an association between disease severity and D2R across patients, this might be true for the individual patient. The decline of SORs in non-operated patients is faster than the $5 \%$ per decade previously reported in the literature in normal subjects (Laruelle et al., 1995); for this reason it is unlikely that the slightly longer time interval between the first and second scan in this group is the cause of the lowered D2R binding. Future imaging studies on the effects of disease progression and the effects of DBS in larger groups of M-D patients having undergone and not having undergone DBS are needed to test this hypothesis.

In conclusion, this study confirms the clinical efficacy of GPiDBS in $\mathrm{M}-\mathrm{D}$, that is not paralleled by any discernable changes on the dopaminergic pathways as measured with [123-I]-IBZM SPECT. In non-operated $\mathrm{M}-\mathrm{D}$ patients $\mathrm{D} 2 \mathrm{R}$ binding seems to have lowered even further, possibly reflecting a stabilizing effect of GPi-DBS on the dopaminergic pathways.

\section{ACKNOWLEDGMENTS}

This study was supported by the following research grants: NWOVIDI grant (project 016.056.333, to R. J. Beukers and M. A. J. Tijssen), and the ONWA-meetfonds (ABIP).

and Tijssen, M. (2009). Reduced striatal D2 receptor binding in myoclonus-dystonia. Eur. J. Nucl. Med. Mol. Imaging 36, 269-274.

Booij, J., Korn, P., Linszen, D. H., and van Royen, E. A. (1997). Assessment of endogenous dopamine release by methylphenidate challenge using iodine-123 iodobenzamide single-photon emission tomography. Eur. J. Nucl. Med. 24 674-677.
Burke, R. E., Fahn, S., Marsden, C. D., Bressman, S. B., Moskowitz, C., and Friedman, J. (1985). Validity and reliability of a rating scale for the primary torsion dystonias. Neurology $35,73-77$.

Cif, L., Valente, E. M., Hemm, S., Coubes, C., Vayssiere, N., Serrat, S., Di Giorgio, A., and Coubes, P. (2004). Deep brain stimulation in myoclonus-dystonia syndrome. Mov. Disord. 19, 724-727. 
Foncke, E. M., Bour, L. J., Speelman, J. D., Koelman, J. H., and Tijssen, M. A. (2007). Local field potentials and oscillatory activity of the internal globus pallidus in myoclonusdystonia. Mov. Disord. 22, 369-376.

Frucht, S. J., Leurgans, S. E., Hallett, M., and Fahn, S. (2002). The Unified Myoclonus Rating Scale. Adv. Neurol. 89, 361-376.

Gruber, D., Kuhn, A. A., Schoenecker, T., Kivi, A., Trottenberg, T., Hoffmann, K. T., Gharabaghi, A., Kopp, U. A., Schneider, G.-H., Klein, C., Asmus, F., and Kupsch, A. (2010). Pallidal and thalamic deep brain stimulation in myoclonus-dystonia. Mov. Disord. 25, 1733-1743.

Hesse, S., Strecker, K., Winkler, D., Luthardt, J., Scherfler, C., Reupert, A., Oehlwein, C., Barthel, H., Schneider, J. P., Wegner, F., Meyer, P., Meixensberger, J., Sabri, O., and Schwarz, J. (2008). Effects of subthalamic nucleus stimulation on striatal dopaminergic transmission in patients with Parkinson's disease within one-year follow-up. J. Neurol. 255, 1059-1066.

Hilker, R., Voges, J., Ghaemi, M., Lehrke, R., Rudolf, J., Koulousakis, A., Herholz, K., Wienhard, K., Sturm, V., and Heiss, W. D. (2003). Deep brain stimulation of the subthalamic nucleus does not increase the striatal dopamine concentration in parkinsonian humans. Mov. Disord. $18,41-48$.

Ishibashi, K., Ishii, K., Oda, K., Kawasaki, K., Mizusawa, H., and Ishiwata, K. (2009). Regional analysis of age-related decline in dopamine transporters and dopamine D2-like receptors in human striatum. Synapse 63, 282-290.

Klein, C. (2003). "Myoclonus and myoclonus-dystonias," in Genetics of
Movement Disorders, ed. S. M. Pulst (Boston: Academic), 449-469.

Kuncel, A. M., Turner, D. A., Ozelius, L. J., Greene, P. E., Grill, W. M., and Stacy, M. A. (2009). Myoclonus and tremor response to thalamic deep brain stimulation parameters in a patient with inherited myoclonusdystonia syndrome. Clin. Neurol. Neurosurg. 111, 303-306.

Kupsch, A., Benecke, R., Muller, J., Trottenberg, T., Schneider, G. H., Poewe, W., Eisner, W., Wolters, A., Müller, J. U., Deuschl, G., Pinsker, M. O., Skogseid, I. M., Roeste, G. K., Vollmer-Haase, J., Brentrup, A., Krause, M., Tronnier, V., Schnitzler, A., Voges, J., Nikkhah, G., Vesper, J., Naumann, M., Volkmann, J., and Deep-Brain Stimulation for Dystonia Study Group. (2006). Pallidal deep-brain stimulation in primary generalized or segmental dystonia. N. Engl. J. Med.355, 1978-1990.

Kurtis, M. M., San Luciano, M., Yu, Q., Goodman, R. R., Ford, B., Raymond, D., Pullman, S. L., and SaundersPullman, R. (2010). Clinical and neurophysiological improvement of SGCE myoclonus-dystonia with GPi deep brain stimulation. Clin. Neurol. Neurosurg. 112, 149-152.

Laruelle, M., Abi-Dargham, A., van Dyck, C. H., Rosenblatt, W., ZeaPonce, Y., Zoghbi, S. S., Baldwin, R. M., Charney, D. S., Hoffer, P. B., Kung, H. F., and Innis, R. B. (1995). SPECT imaging of striatal dopamine release after amphetamine challenge. J. Nucl. Med. 36, 1182-1190.

Nakajima, T., Nimura, T., Yamaguchi, K., Ando, T., Itoh, M., Yoshimoto, T., and Shirane, R. (2003). The impact of stereotactic pallidal surgery on the dopamine D2 receptor in Parkinson disease: a positron emission tomography study. J. Neurosurg. 98, 57-63.

Valldeoriola, F., Regidor, I., MínguezCastellanos, A., Lezcano, E., GarciaRuiz, P., Rojo, A., Salvador, A., Castro, A., Grandas, F., Kulisevsky, J., Martí, M. J., Martínez-Martín, P., Relova, L., Rumià, J., Cámara, A., Burguera, J. A., Linazasoro, G., de Val, J. L., Obeso, J., Rodríguez-Oroz, M. C., Tolosa, E., and Grupo Español para el Estudio de la Estimulación Palidal en la Distonía. (2010). Efficacy and safety of pallidal stimulation in primary dystonia: results of the Spanish multicentric study. J. Neurol. Neurosurg. Psychiatr. 81, 65-69.

Vidailhet, M., Vercueil, L., Houeto, J. L., Krystkowiak, P., Benabid, A. L., Cornu, P., Lagrange, C., Tézenas du Montcel, S., Dormont, D., Grand, S., Blond, S., Detante, O., Pillon, B. Ardouin, C., Agid, Y., Destée, A., Pollak, P., and French Stimulation du Pallidum Interne dans la Dystonie (SPIDY) Study Group. (2005). Bilateral deep-brain stimulation of the globus pallidus in primary generalized dystonia. N. Engl. J. Med. 352, 459-467.

Vidailhet, M., Vercueil, L., Houeto, J. L., Krystkowiak, P., Lagrange, C., Yelnik, J., Bardinet, E., Benabid, A. L., Navarro, S., Dormont, D., Grand, S., Blond, S., Ardouin, C., Pillon, B., Dujardin, K., Hahn-Barma, V., Agid, Y., Destée, A., Pollak, P., and French SPIDY Study Group. (2007). Bilateral, pallidal, deep-brain stimulation in primary generalised dystonia: a prospective 3 year follow-up study. Lancet Neurol. 6, 223-229.

Vitek, J. L. (2002). Pathophysiology of dystonia: a neuronal model. Mov. Disord. 17, S49-S62.

Yokoi, F., Dang, M. T., Li, J., and Li, Y. (2006). Myoclonus, motor deficits, alterations in emotional responses and monoamine metabolism in epsilon-sarcoglycan deficient mice. J. Biochem. 140, 141-146.

Zimprich, A. F., Grabowski, M. F., Asmus, F. F., Naumann, M. F., Berg D. F., Bertram, M. F., Scheidtmann, K., Kern, P., Winkelmann, J., MüllerMyhsok, B., Riedel, L., Bauer, M., Müller, T., Castro, M., Meitinger, T., Strom, T. M., and Gasser, T. (2001). Mutations in the gene encoding epsilon-sarcoglycan cause myoclonus-dystonia syndrome. Nat. Genet. 29, 66-69.

Conflict of Interest Statement: The authors declare that the research was conducted in the absence of any commercial or financial relationships that could be construed as a potential conflict of interest.

Received: 07 September 2011; paper pending published: 11 November 2011 accepted: 03 February 2012; published online: 20 February 2012

Citation: Beukers RJ, Contarino MF, Speelman JD, Schuurman PR, Booij J and Tijssen MAJ (2012) Deep brain stimulation of the pallidum is effective and might stabilize striatal $D_{2}$ receptor binding in myoclonus-dystonia. Front. Neur. 3:22. doi: 10.3389/fneur.2012.00022

This article was submitted to Frontiers in Movement Disorders, a specialty of Frontiers in Neurology.

Copyright (c) 2012 Beukers, Contarino, Speelman, Schuurman, Booij and Tijssen. This is an open-access article distributed under the terms of the Creative Commons Attribution Non Commercial License, which permits noncommercial use, distribution, and reproduction in other forums, provided the original authors and source are credited. 